\title{
South Atlantic Anomaly, Ionospheric Signals from Seismic Events
}

\author{
Marilia Hagen"1, Anibal Azevedo² \\ ${ }^{1}$ Nashville, Indiana, USA; ${ }^{2}$ Faculdade de Ciências Aplicadas da Unicamp, Limeira, São Paulo, Brazil \\ Correspondence to: Marilia Hagen, marhagen@iu.edu; Anibal Azevedo, anibal.azevedo@fca.unicamp.br
}

Keywords: South Atlantic Anomaly, Ionosphere Signs, Earthquake Prediction

Received: February 24, $2020 \quad$ Accepted: March 15, $2020 \quad$ Published: March 18, 2020

Copyright (c) 2020 by author(s) and Scientific Research Publishing Inc.

This work is licensed under the Creative Commons Attribution International License (CC BY 4.0).

http://creativecommons.org/licenses/by/4.0/

\section{(c) (i) Open Access}

\section{ABSTRACT}

The purpose of this paper is to analyze the most significant events that occurred in the period 1996-2018 located under the South Atlantic Anomaly (SAA), where the earth's magnetic field is weaker and the trapped particles during the geomagnetic storms suffer decay over time. The time examined corresponds to the Solar Cycles 23 and 24; the area covered is defined by the following coordinates: $0 \mathrm{~N},-50 \mathrm{~S}, 40 \mathrm{E},-90 \mathrm{~W}$. Some significant events in this region reported Very Low Frequency (VLF) and Ultra Low Frequency (ULF) waves before the event, varying from minutes, hours, and even weeks before the earthquakes. Our study searches for a mechanism to explain why the crust creates electromagnetic signs detected at the ionosphere. Piezoelectric currents flow on the crust, combining with the magnetic field lines, temporarily producing pre-seismic electromagnetic pulses that are detected at the ionosphere prior to the events. The mechanism that allows electromagnetic signs to be detected at the ionosphere is also elucidated. These signs are brief, and they will cease with the beginning of the shock or shortly thereafter. However, some features contribute to making the signs impossible to detect, involving crust materials, location, magnitude, and depths. We suggest that these ionospheric events could happen for other kinds of hazard events, such as Volcanos.

\section{INTRODUCTION}

The South Atlantic Anomaly (SAA) is the weak region of the Earth's magnetic field centered over South America, which allows the inner Van Allen radiation belt to be closer to the atmosphere. The territory covered by SAA is focused on South America, and is also the area where the Earth's inner Van Allen's radiation belt is closest to the Earth's surface. This drives an increased flux of energetic particles, becoming the maximum in the region. During geomagnetic storms, the flux of relativistic electrons in the Van Allen 
radiation belts can vary by up to five orders of magnitude [1]. These electrons are free to move since the Earth's magnetic field is weaker in this region. The ionized particles in the Van Allen belts come from the Sun from reconnection at the dayside magnetosphere by the poles. They also come from the reconnection at the nightside as in Figure 1. Figure 1 shows the Earth's magnetic field lines and the points of reconnection at the dayside and nightside. If a great geomagnetic storm happens, the location (SAA) is filled by energy electrons that are trapped, as observed by NOAA-16 satellite, with $100-300 \mathrm{keV}$ electrons at very low latitude [2]. Figure 2 is the location of the SAA on a worldwide map, the magnetic field magnitude is displayed by color and shows the location of South Atlantic anomaly in comparison with the rest of the Earth. The anomaly intensity is higher in South America.

Under SAA, the weakness of the magnetic field is unable to isolate the Earth's surface; therefore, the accumulating ionized particles will create discharges, plasma bubbles (most at nighttime), into the region, eventually releasing electromagnetic charges to Earth's surface [3, 4]. Figure 3 shows the magnitude variation

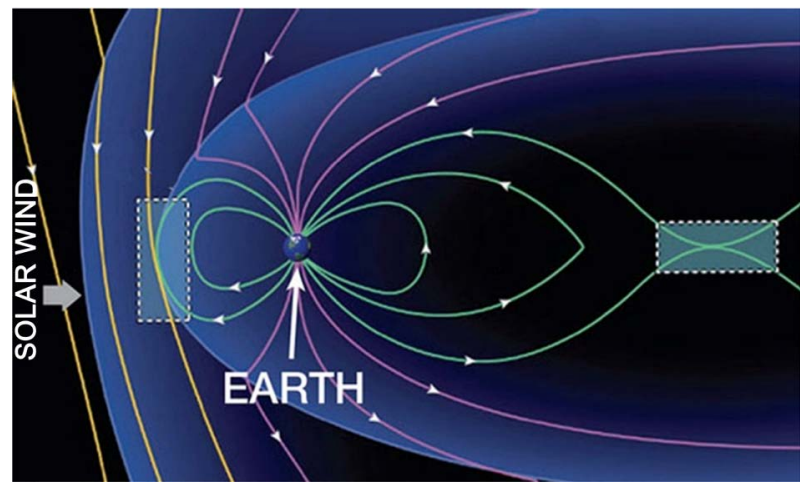

Figure 1. There are two points of reconnection in the magnetosphere, one on the dayside, and the other at night side.

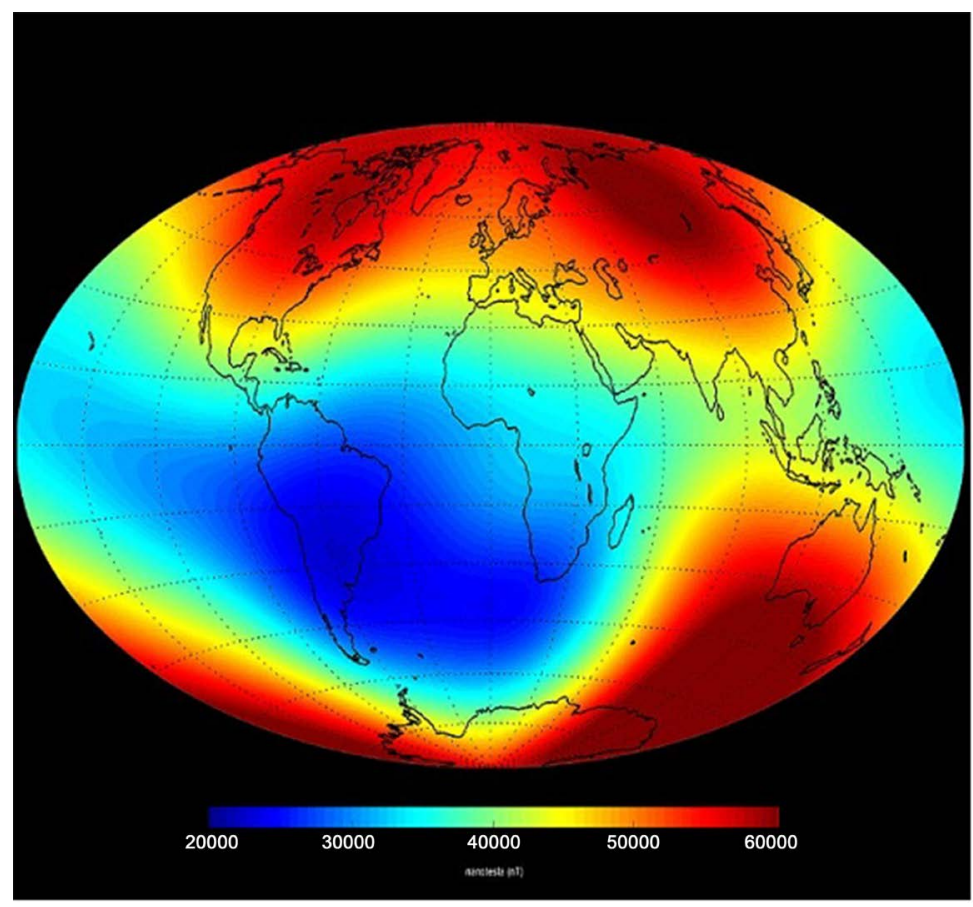

Figure 2. Figure shows the South Atlantic anomaly region and magnitudes. Dark color shows the intensity of the magnetic field in nanotesla. 


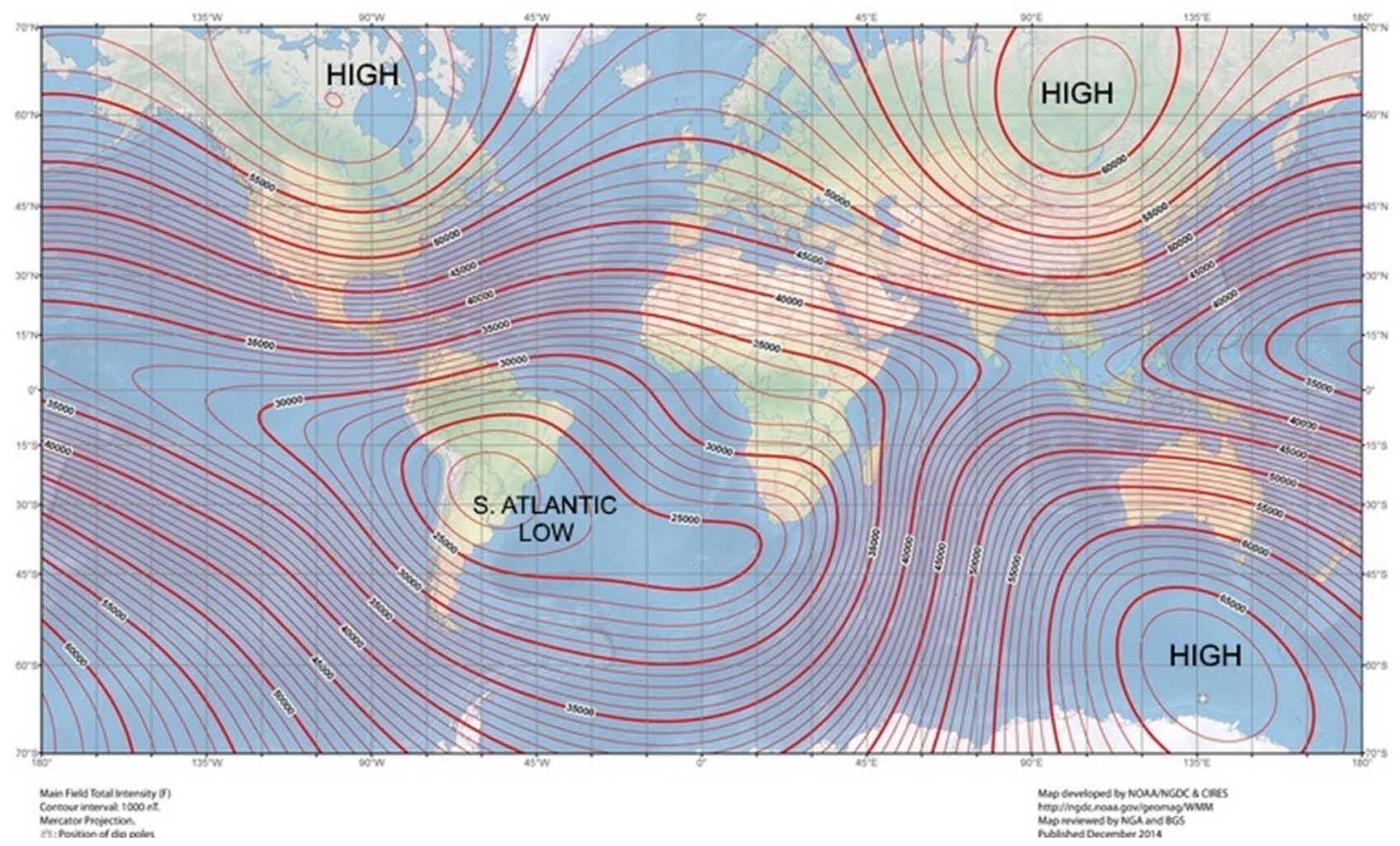

Figure 3. It shows the worldwide distribution of the magnetic field and South Atlantic anomaly. It compares the higher magnetic field areas and the South Atlantic anomaly low.

on the SAA, and other regions considered as having higher field intensity, and the values are also presented. The area coordinates are 0N, $-50 \mathrm{~S}, 40 \mathrm{E},-90 \mathrm{~W}$. The period studied is 1996-2018, or two Solar Cycles. Figure 3 displays the distribution of the world magnetic field, comparing the regions with high magnetic fields and lower magnetic fields. Domingos et al. have found that the eccentric dipole is currently offset from the Earth's center by about $550 \mathrm{~km}$ in a direction approximately 220N, 1400E [5].

We investigate the largest magnitude earthquakes, $\geq$ M7.5, occurring at the Southern Pacific subduction zones. These large events have puzzled scientists with pre-seismic signs, which are supposed to forecast the events before they happen. Although some scholars have found electromagnetic signs created from rocks [6-8], claiming that they will be detected at the ionosphere [9-11], it is still not clear about the propagation mechanism between the Earth's ground and the ionosphere $[12,13]$.

There are studies that have described the alternating currents created by tension and pressure on the rocks, such as crystals, salt, quartz, and feldspar [14-17].

Tsutsumi has shown that electromagnetic signals are also emitted during the deformation of quartz-free rocks, such as basalt and peridotite [6]. These signs from the Earth's crust can combine with the Earth's magnetic field generating VLF, ULF, and ELF frequencies sent to the ionosphere [18-20]. The phenomena happen earlier than an earthquake event; therefore, the detection scenario in the ionosphere will occur minutes, hours, days, or even weeks before the tremor. There is a close dependence with the magnitude, as well the depth of the quake and the power of the signs sensed.

Pre-seismic signs are not the only ones to be perceived at the ionosphere; there are at least three examples of how megathrust earthquakes are affected the higher levels of the atmosphere. First, the Sumatra (2004), where the ionosphere disturbances occurred approximately 20 minutes and the second one $>3$ 
hours after the earthquakes [19]. Co-seismic ionosphere disturbances were also observed after the 2002 Denali earthquakes [18], and 755 aftershocks were reported at maximum magnitudes, M5.6 [19]. Finally, the earthquakes in Tohoku, Japan (2011), which had intense pre-seismic activity of M7.7, the highest, and post-seismicity of 1065 events with M6.1 as a maximum [20].

We propose that the main earthquakes create successive anomalies at the ionosphere, including pre-seismic, co-seismic and post-seismic, where the first two are dependent on the depth /magnitude and the last depends on the intensity of the aftershocks.

The mechanism described here involves the alternating currents on the crustal Earth's surface, with an interaction of the Earth's magnetic field. Although these signs may be intense over the most significant events and the ionosphere will remain disturbed for a while, eventually they will cease being absorbed, turn to mechanical waves, and disperse around the epicenter.

\section{SOUTH ATLANTIC ANOMALY AND EXPERIMENTAL DATA}

This paper deals with the South Atlantic anomaly region, as explained before, and the coordinates are $0 \mathrm{~N},-50 \mathrm{~S}, 40 \mathrm{E},-90 \mathrm{~W}$, see Figure 1. The occurrences are all at the Southern of the Pacific side of South America. Here, it uses the data from the USGS and Iris catalogs, both offering complementary records to each other; however, only the USGS map displays the region recorded in a way it can be shared by location occurred [21,22].

\section{LARGEST EARTHQUAKES UNDER SOUTH ATLANTIC ANOMALY}

Table 1 shows the 17 major events occurring in the area during the period analyzed. The columns are

Table 1. Largest earthquakes with magnitude, depth, and data occurred during the period 1996-2019.

\begin{tabular}{cccc}
\hline Location & Date & Mag. & Depth (km) \\
\hline Off coast N. Peru & $21-02-96$ & 7.5 & 33 \\
Near coast Central Peru & $12-11-96$ & 7.7 & 33 \\
Near coast Southern Peru & $23-06-01$ & 8.4 & 33 \\
Near coast Southern Peru & $07-07-01$ & 7.6 & 33 \\
Tarapaca, Chile & $13-06-05$ & 7.8 & 115.6 \\
Northern Peru & $26-09-05$ & 7.5 & 115 \\
Near coast Central Peru & $15-08-07$ & 8 & 39 \\
Antofagasta, Chile & $11-14-07$ & 7.7 & 40 \\
Maule, Chile & $02-27-10$ & 8.8 & 22.9 \\
94 km NW, Iquique, Chile & $04-01-14$ & 8.2 & 25 \\
53 km SW Iquique, Chile & $04-03-14$ & 7.7 & 22.4 \\
48 km W Illapel, Chile & $09-16-15$ & 8.3 & 22.4 \\
173 km WNW Iberia, Peru & $11-24-15$ & 7.6 & 606.6 \\
211 km S Tarauaca, Brazil & $11-24-15$ & 7.6 & 620.6 \\
$41 \mathrm{~km}$ SW Puerto Quellon, Chile & $12-25-16$ & 7.6 & 38 \\
$111 \mathrm{~km}$ ESE of Palora, Ecuador & $22-02-19$ & 7.5 & 145 \\
78 km SE Lagunas, Peru & $26-05-19$ & 8 & 122.6 \\
\hline
\end{tabular}


location, date, magnitude, and depth of each big earthquake. The first event recorded was in 1996, off the coast of Peru, with one of the lowest magnitudes documented. We also observe that frequency and magnitude have enhanced in the region since then. To understand better what is the interaction between the earthquakes and other events at the Earth's crust, it is necessary to know how they will happen at subduction regions, such as the one investigated below. Figure 4, showing the main location of such earthquakes and the color indicate how deep it was the occurrences.

The surface of the Earth consists of some plates, comprising of the upper mantle. These plates are always moving, thus affecting the Earth's crust. These movements are categorized into three types: constructive, destructive, and conservative. Constructive is when two plates move away from each other; they correspond to mild earthquakes. When two plates move towards each other and collide, this is known as destructive plate boundaries. Conservative corresponds to passing plates of crust. Earthquakes of this type have varying intensity. A geological fault is known as the displacement of plates of their original plane. The plane can be horizontal or vertical. These planes are not formed suddenly, but slowly developed over a long period. The movement of rocks along these planes brings about tectonic earthquakes. In subduction zones, such as Nazca Plate and South America, earthquakes are caused by shifts over an area of the plate interface called the seismogenic zone. Examining the date of events, we observed that these events are shallow and happen most frequently in the Spring or Summer in the area. The depth exceptions will play different roles for this paper, as we are going to see later. Table 2 shows the same events with a different assessment, location, date of the events, aftershocks' deepest depth, number of aftershocks with the same depth, and the last column with foreshocks and corresponding depths. The number of aftershocks is not a total of them, but rather the most common at the referenced depth. Comparing Table 1 and Table 2, it is clear that the majority of aftershocks have their epicenter at the same depth as the original shock; these differences are sharp for Chilean earthquakes.

Table 2 also ignores the last two events that occurred in 2019; there are no posterior records of anomalies in the ionosphere for those two events since they were recent. These two tables establish the biggest events that happened during the two solar cycles, as well as some records about the aftershocks and foreshocks that will be used later in this paper.

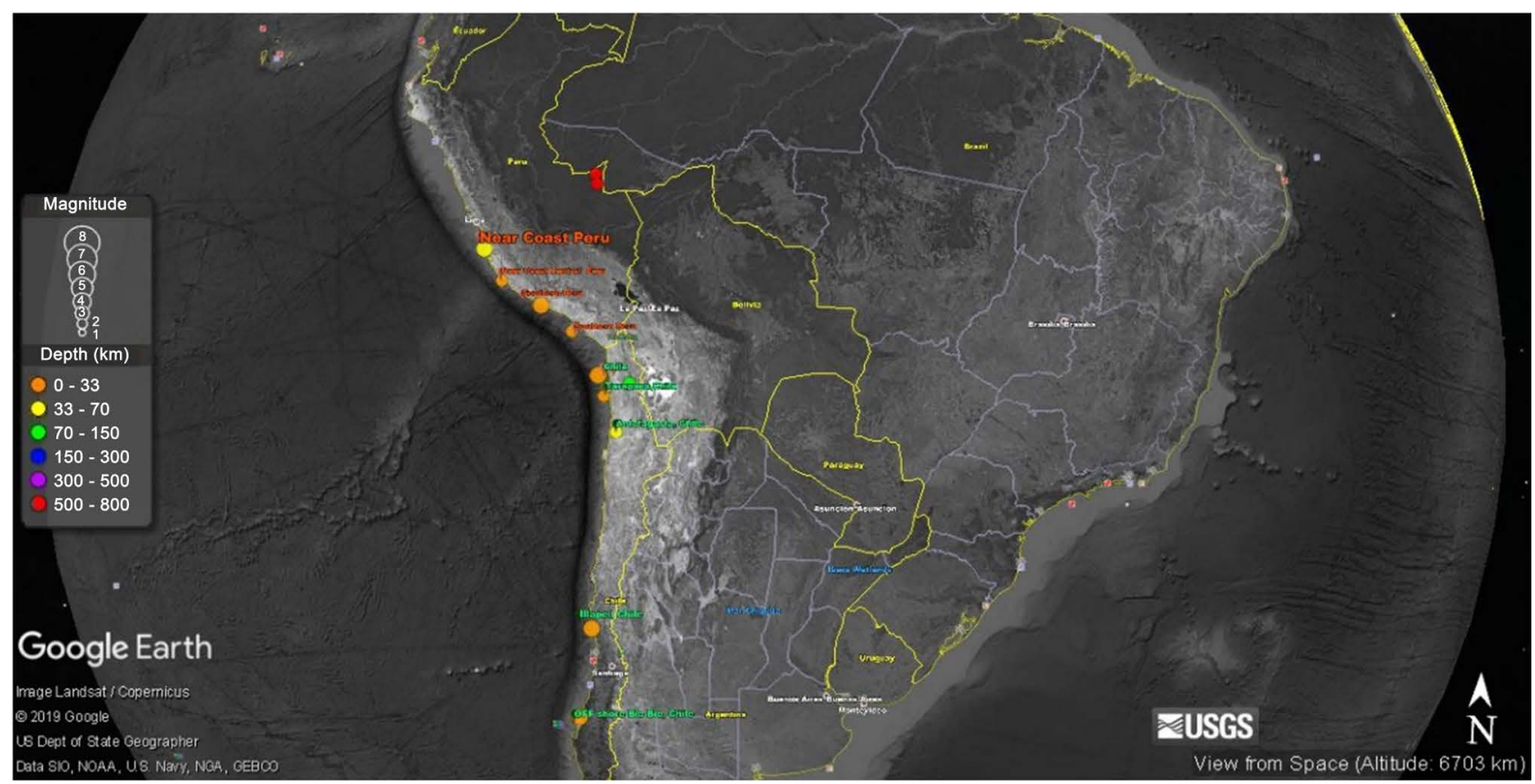

Figure 4. The largest earthquakes under South Atlantic anomaly period 1996-2018. Observe the depth colors, the deepest earthquakes are in red in the picture. 
Table 2. Earthquakes with magnitude $\geq 7.5$ at the South Atlantic anomaly area. The chart showing the location, date, aftershocks depths, number of aftershocks, foreshocks number, and the respective depth.

\begin{tabular}{ccccc}
\hline Location & Date & $\begin{array}{c}\text { Aftershock } \\
(\sim \text { depths })\end{array}$ & $\begin{array}{c}\mathbf{N}^{\circ} \\
\text { aftershocks }\end{array}$ & $\begin{array}{c}\text { Foreshocks } \\
\text { depths }\end{array}$ \\
\hline Off coast N. Peru & $21-02-96$ & $33 \mathrm{~km}$ & 19 & $6(33 \mathrm{~km})$ \\
Near coast Central Peru & $12-11-96$ & $33 \mathrm{~km}$ & 63 & $6(33 \mathrm{~km})$ \\
Near coast South Peru & $23-06-01$ & $33 \mathrm{~km}$ & 394 & none \\
Near coast South Peru & $07-07-01$ & $33 \mathrm{~km}$ & 118 & $84(33 \mathrm{~km})$ \\
Tarapaca, Chile & $13-06-05$ & $>100$ & 60 & $16(>100 \mathrm{~km})$ \\
Northern Peru & $26-09-05$ & none & none & none \\
Near coast Central Peru & $15-08-07$ & $35-40 \mathrm{~km}$ & 69 & none \\
Antofagasta, Chile & $11-14-07$ & $35-39 \mathrm{~km}$ & 30 & none \\
Maule, Chile & $02-27-10$ & $35-40 \mathrm{~km}$ & 284 & none \\
$94 \mathrm{~km}$ NW, Iquique, Chile & $04-01-14$ & $10 \mathrm{~km}$ & 132 & none \\
$53 \mathrm{~km}$ SW Iquique, Chile & $04-03-14$ & $25 \mathrm{~km}$ & 173 & $102(10-20 \mathrm{~km})$ \\
$48 \mathrm{~km}$ W Illapel, Chile & $09-16-15$ & $10 \mathrm{~km}$ & 237 & none \\
$173 \mathrm{~km}$ WNW Iberia, Peru & $11-24-15$ & none & none & none \\
$211 \mathrm{~km}$ S Tarauaca, Brazil & $11-24-15$ & none & none & none \\
$41 \mathrm{~km}$, SW Puerto Quellon, Chile & $12-25-16$ & $10-20 \mathrm{~km}$ & 10 & none \\
\hline
\end{tabular}

\section{PIEZOELECTRIC EFFECTS IN THE EARTH'S CRUST}

The last part of our paper is to study how the events mentioned were able to imprint ionosphere signs. Table 3 displays the location, date, magnitude, and the last one the ionosphere reports. The three first ones had no reports available neither for the one very deep; for the last depth answers, when the earthquakes are very deep, they will not send electromagnetic signs strong enough to the ionosphere prior to or after the earthquakes. To understand the mechanism from ground to ionosphere, this paper is divided into two steps. The first is to understand the generation of current and electric fields on the ground and how components $\mathbf{E}$ and $\mathbf{B}$ perpendicular for each other will combine creating a transverse electromagnetic pulse traveling into the resonant cavity formed by ground and ionosphere, these signs are VLF, ULF, Extra Low Frequencies (ELF) and Total Electron Content (TEC), [14-16].

The piezoelectric effect is a unique property of certain materials that generate an electric field, or current, subjected to physical stress. The same effect can also be observed in reverse, where an imposed electric field on a crystal will put pressure on its structure $[17,18]$.

The electric flux from the rocks' stress, compression, and tension, can generate an AC (alternating current) voltage when subject to mechanical pressure or vibration. The flow under some circumstances will emit radiation, known as low frequencies, that are detected in the ionosphere. Mathematically,

$$
V_{p e}=D \times T
$$

$V_{p e}$ is the piezoelectric polarization vector,

$D$ is the piezoelectric strain coefficient,

$T$ is the stress applied to the rock.

This equation describes how a rock can create an AC electric current, due to stress, compression, or 
other kinds of strain. From this equation, if there is more pressure, the electrical current increases. Those ionized particles can be enhanced by other telluric currents in the region, but the mechanism to have an electromagnetic wave is a joint effect on Earth's magnetic field, $\mathbf{B}$. The combination of those two fields are the transversal waves, known as low frequency waves, that will send an imprint to the resonant cavity between Earth's surface and ionosphere. Most of those signs are VLF, ELF, ULF, or the named TEC disturbances, in Figure 5.

The disturbances at the ionosphere happen earlier than an earthquake; however, they will disappear, be absorbed, or transform into a mechanical event, as observed on seismic waves.

Electromagnetic waves are faster than mechanical waves and, depending on the material under pressure, they are able to propagate to the atmosphere and ionosphere. The space between the Earth's surface and ionosphere is a resonance cavity, allowing the electromagnetic signs to propagate. This explains why large earthquakes easily send electromagnetic waves detected minutes, hours, days, or even weeks at the ionosphere before they strike; therefore, it is a perfect forecast for big earthquakes.

Next, we discuss how these waves are formed and how they will replicate and refract at the ionosphere.

\section{MECHANISM AND ORIGIN TEMPORARY IONOSPHERIC SIGNS}

Electromagnetic waves are synchronized oscillations of electric and magnetic fields. The Earth's magnetic field $B$ is approximately a dipole with larger magnitude at the poles and lower magnitude around the equator. At the location analyzed, SAA is even lower. Pre-seismic signs for most big earthquakes at this location have been reported as Table 3 shows.

We propose piezoelectric currents as transitory and created by friction, strain, and pressure on the material on Earth's surface prior to the earthquake, flowing as an electric component perpendicular to the magnetic field generating transversal waves. Electromagnetic waves carry energy as they travel in the resonance cavity between Earth's surface and ionosphere. The energy density is associated with electric field $E$ by the piezo electric currents and the Earth's magnetic field $B$. Both fields are oscillatory, and, by Maxwell equations, we have:

For the electric field,

$$
E=E_{\max } \sin (k x-\omega t+\varphi)
$$

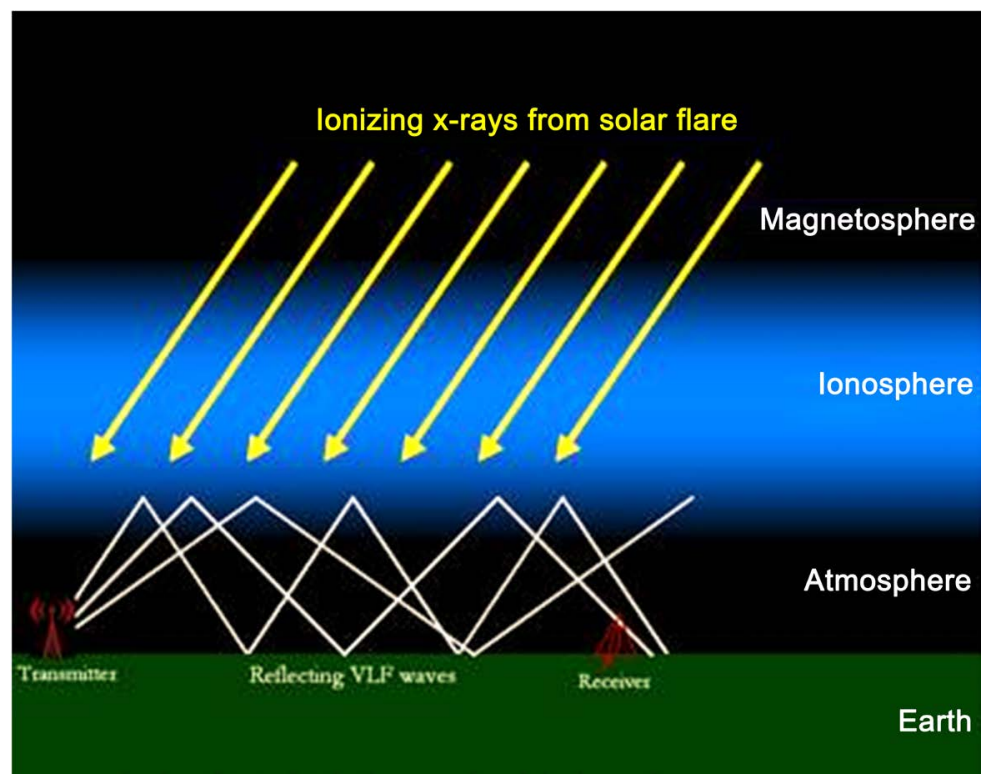

Figure 5. Resonant cavity between the ionosphere and earth's surface. 
$E_{\max }$ is the amplitude,

$\omega$ is the angular frequency (in radians per second),

$k x$, is the wave vector (in radians per meter),

and

$\varphi$ is the phase angle (in radians).

For the magnetic earth field,

$$
B=B_{\max } \sin (k y-\omega t+\varphi)
$$

$B_{\max }$ is the amplitude,

$\omega$ is the angular frequency (in radians per second),

$k y$, is the wave vector (in radians per meter),

and

$\varphi$ is the phase angle (in radians).

The components of these fields will combine and will travel transversal for both reaching the ionosphere, and we can express the energy they create by the Poynting vector, expressed by the vector product, supposing $E$ is the electric field from the piezo currents and $B$ is the Earth's magnetic field; therefore, the energy density is expressed by:

$$
S=1 / \mu_{0} E \times B
$$

$S$ is the energy density,

$\mu_{0}$ is the vacuum permissity,

$E$ is the electric field created by the electric current prior the earthquake,

$B$ is the earth's magnetic field.

This expression is a vector product of the oscillatory fields, once the magnetic field is perpendicular to the electric field the magnitude of the energy density may be written as:

$$
S=1 / \mu_{0} E B
$$

This expression is the density energy created by $E$ perpendicular to $B$ creating a transversal pulse able to propagate between ground and ionosphere, Figure 6 .

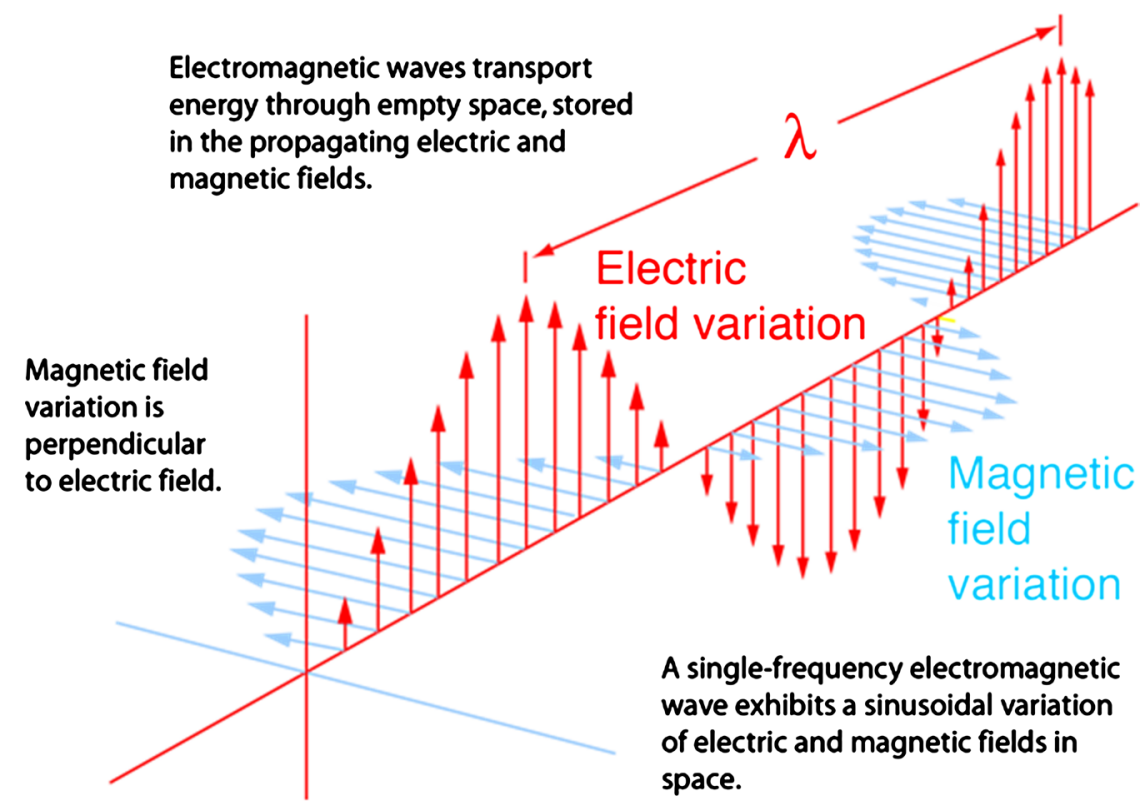

Figure 6 . The temporary electromagnetic waves created by the $\mathrm{E} \times \mathrm{B}$ product the $\mathrm{E}$ is an alternating current by piezoelectric materials and B is the Earth's magnetic field, both are pulsating on time. 
Figure 6 shows how these two fields combine to create a magnetic wave that varies in the range of VLF or ULF, moving in the ionosphere direction. These waves can travel through a medium and a vacuum. The propagation of these electromagnetic waves from the Earth's surface through the atmosphere, which is a resonating cavity, and the ionosphere, being a receiver. The ionosphere layer is a reflector for low frequencies and large lengths. Electromagnetic waves with frequencies higher than $30 \mathrm{MHz}$ penetrate the ionosphere and escape.

In this case, we are associating a combination of Earth's magnetic field and the alternate currents generated temporarily underground with a large wavelength and low frequency for a while. These EM emissions, due to the piezoelectric materials, are able to be detected several hours and even weeks before the seismic events occur.

However, some factors remain important to the detection of these pre-seismic ionosphere anomalies. Concerning the magnitude of the earthquakes, highest magnitudes have a considerable amount of strain, friction, and stress at the rocks nearby; therefore, magnitudes above seven may be detected earlier. Nevertheless, another factor that seems to be important, as Table 3 shows, the earthquakes deepest depth did not have ionosphere disturbances reported. These signs, for depths $\geq 200 \mathrm{~km}$, were not detected. Our studies were not able to find ionosphere disturbances reported for deep events. The signs at the ionosphere will cease as soon the electric currents disappear or during the earthquake when mechanical waves are also released; therefore, some of the ground electricity will be dissipated in mechanical energy. There are indications that the aftershocks, depending on the intensity and magnitude, might imprint on the ionosphere as well.

\section{WHAT ARE THE ULF, VLF AND TEC SIGNS DETECTED ON IONOSPHERE}

The ionosphere is the ionized part of the Earth's upper atmosphere, located above $600 \mathrm{~km}-1000 \mathrm{~km}$. Radio propagation happens in the ionosphere to distant places, worldwide. The ionosphere is divided into three layers: $\mathrm{F}$ layer, at the top, is the only layer with high ionization at night, where $\mathrm{E}$ and $\mathrm{D}$ are low. During the day, $\mathrm{D}$ and $\mathrm{E}$ become more ionized and $\mathrm{F}$ is divided in two: $\mathrm{F}_{1}$ (weaker ionization) and $\mathrm{F}_{2}$, which is responsible for the refraction and reflection of radio waves. The $\mathrm{F}$ layer during the night becomes a layer $F_{2}$ and a secondary layer $F_{1}$ appear during the day. Since $F_{2}$ persists day and night, it is where the propagation of radio waves is detected. This region suffers anomalies during the seasons, as winter anomaly does not exist in the Southern Hemisphere during periods of low solar activity. Another one is the equatorial anomaly, which is where the Earth's magnetic lines are horizontal around the magnetic equator. It concentrates ionization up into the F layer. There is an equatorial electrojet named Solar quiet (Sq.) current system in the $\mathrm{E}$ region of the ionosphere and results in an electrostatic field directed west-east (same direction of Earth's rotation) in the equatorial dayside of the ionosphere. The X-rays from solar storms, penetrating $\mathrm{D}$ region, release electrons increasing absorption and causing a high frequency radio blackout. During this time, VLF (very low frequency) signals are reflected by the D layer instead of E layer, where the enhanced atmospheric density will increase absorption of the wave and thus dampen it. It will stop when sudden ionospheric disturbances (SID), or radio- blackout, end and the electrons in the D region recombine. Sometimes solar flares will cause geomagnetic storms disturbing the Earth's magnetosphere. The $\mathrm{F}_{2}$ layer becomes unstable, fragmented and may disappear completely. Extremely low frequency (ELF) for electromagnetic radiation (radio waves), with frequencies from $3 \mathrm{~Hz}$ to $3 \mathrm{kHz}$, are generated by natural disturbances in the Earth's magnetic field. ELF is a sub-radio frequency due to its extremely long wavelength diffracting along large obstacles; they are not blocked by mountain ranges and travel around the curve of the Earth. The D layer of ionosphere reflects ELF waves. ELF can travel considerable distances through media, like earth or sea water, which would reflect or absorb higher frequency radio waves. The next of our detected waves are the VLF, from 3 to $30 \mathrm{kHz}$, which diffract around large obstacles. VLF waves are reflected by D layer $(60-90 \mathrm{~km})$. Finally, the total electron content (TEC) is the total number of electrons present along a path between radio transmitter and receiver. Radio waves are affected by the presence of electrons; if there are more electrons in the path of the radio wave, more the radio signal will 
be affected. Next, we will explain the mechanism among Earth and the ionosphere and the waves created in the resonant cavity between them and how the alternating currents flow near the Earth's surface and the perpendicular magnetic field from the Earth are able to create a transversal wave, which will be detected in the ionosphere.

\section{DATA AND RESULTS DISCUSSION}

Table 3 shows ionosphere reports from different events in South America. First column is the events place, second, date of occurrence, third the magnitude, the last is the determination of pre seismic events reports and the reference numbers.

The first three events do not present available records in papers; the other two from 2015 indicate the depths are an essential issue and whether or not the event had a deep depth and did not present ionosphere disturbances. Observe for example, the event in Tarapaca, Chile occurred in 2005, did not have ionospheric events reports the depth of the earthquake was $115.6 \mathrm{~km}$, other two events as Iberia, Peru (606.6 $\mathrm{km})$ and Tarauaca, Brazil $(620.6 \mathrm{~km})$ did not have ionospheric reports as well.

As described earlier, some factors have paramount reasons to disturb the ionosphere enough to be detected on the ground or by satellite instruments. Piezoelectric currents must be combined with the B perpendicular component related to the electric field on the ground to produce a transversal wave with low frequencies. Many authors reported the time before the earthquakes reproduce ionospheric disturbances is, at most, 30 minutes before the event in the region of SAA.

However, it changes concerning other areas, depending on some factors, such as crustal surface and the tremor epicenter. A question arises: what earthquake magnitude may create electromagnetic waves strong enough to detect at the ionosphere before the hit? It depends most on the crustal surface in the region, location of a fault, subduction, epicenter depth, and stress of the rocks, which are the main issues.

For example, some authors detected SELF-VLF electromagnetic signals in Central Italy for an

Table 3. The events which report ionospheric signs are below.

\begin{tabular}{cccc}
\hline Location & Date & Mag. & Ionosphere reports \\
\hline Off coast N. Peru & $21-02-96$ & 7.5 & No \\
Near coast Central Peru & $12-11-96$ & 7.7 & No \\
Near coast Southern Peru & $23-06-01$ & 8.4 & No \\
Near coast Southern Peru & $07-07-01$ & 7.6 & Yes [13] \\
Tarapaca, Chile & $13-06-05$ & 7.8 & No \\
Northern Peru & $26-09-05$ & 7.5 & Yes [12, 13] \\
Near coast Central Peru & $15-08-07$ & 8 & Yes [13] \\
Antofagasta, Chile & $11-14-07$ & 7.7 & Yes [12] \\
Maule, Chile & $02-27-10$ & 8.8 & Yes [10, 12] \\
$94 \mathrm{~km}$ NW, Iquique, Chile & $04-01-14$ & 8.2 & Yes [12] \\
$53 \mathrm{~km}$ SW Iquique, Chile & $04-03-14$ & 7.7 & Yes [12] \\
$48 \mathrm{~km}$ West Illapel, Chile & $09-16-15$ & 8.3 & Yes [12] \\
$173 \mathrm{~km}$ WNW Iberia, Peru & $11-24-15$ & 7.6 & No \\
$211 \mathrm{~km}$ South Tarauaca, Brazil & $11-24-15$ & 7.6 & No \\
$41 \mathrm{~km} \mathrm{SW} \mathrm{Puerto} \mathrm{Quellon,} \mathrm{Chile}$ & $12-25-16$ & 7.6 & Yes [13]
\end{tabular}


earthquake with M6.2, on August 24, 2016 with a shallow depth [23]. The event disturbed the ionosphere several hours prior to the seismic event, and it could be a presumption about the magnitude being above M6 in a highly populated region.

Meloni et al. [24] described several other ionospheric signals, most occurring at the location 42.23N, 13.19E. Their list included several earthquakes with various magnitudes, M4 to M5.8, and a variety of depths, $5-22 \mathrm{~km}$. As expected, they pointed out weak evidence coupled between the ionosphere and low magnitude events, indicating a close correlation between both parameters; however, they found some promising results for some events recorded as the ones that happened in September and October 1997, with higher magnitudes M5.8 and M5.6. In our data, an incident occurred in Chile with intermediate depth, M7.7, in 2005, and had no indications of ionosphere disturbances. The same happened for events that occurred in 2015 in Iberia, Peru, and South of Tarauaca, Brazil, both with depths $\geq 600 \mathrm{~km}$.

From the seventeen quakes reported in Table 1, the biggest was in Chile (2010), with a shallow depth and the highest number of aftershocks, between 27/05 - 30/09 and a depth of $33 \mathrm{~km}$. Those grander events in a shallow depth showed there was an 'optimum' depth for the aftershocks' swarms depending on the location of the mainshock epicenter. The intermediate events had fewer or no aftershocks.

\section{CONCLUSIONS}

These preliminary results indicate that under the South Atlantic anomaly, the most significant earthquakes of the entire region (defined at the beginning) happened at the Southern Pacific coast of South America. We also discovered that the gap between Earth's surface and ionosphere acts as a resonator cavity in which low-frequency waves can travel, imprinting the ionosphere with disturbances that will be detected before a big event happens in the region. There is a final observation about these ionospheric perturbations, and they are all connected with the area researched. There is a connection between larger magnitudes and shallower earthquakes being proportional to stronger ionosphere instabilities.

Also, the time before the events, depending on how strong the interactions are, the electric field is created by the alternating currents on the ground and the magnetic field $\mathbf{B}$ perpendicular component.

\section{ACKNOWLEDGEMENTS}

Thanks to Charles Hagen to enlightenment me about ULF, VLF, ELF waves propagation.

\section{CONFLICTS OF INTEREST}

The authors declare no conflicts of interest regarding the publication of this paper.

\section{REFERENCES}

1. Hudson, M.K., et al. (2008) Relationship of Van Allen Radiation Belts to Solar Wind Drivers. Journal of Atmospheric and Solar. Terrestrial Physics, 70, 708-729. https://doi.org/10.1016/j.jastp.2007.11.003

2. Aisikinen, T. and Mursula, K. (2005) Filling the South Atlantic Anomaly by Energetic Electrons during a Great Magnetic Storm. Geophysical Research Letters, 32, L16102. https://doi.org/10.1029/2005GL023634

3. Mokhar, M.H., et al. (2019) Ionospheric Perturbation: A Review of Equatorial Plasma Bubble in the Ionosphere. Proceedings of the 2019 International Conference on Space Science and Communication, Johor Bahru, 28-30 July 2019, 28-30. https://doi.org/10.1109/IconSpace.2019.8905970

4. Huang, C.S. (2011) Occurrence of Equatorial Plasma Bubbles during Intense Magnetic Storms. International Journal of Geophysics, 2011, Article ID: 401858. https://doi.org/10.1155/2011/401858

5. Domingos, J., Jault, D., Pais, M.A. and Mandea, M. (2017) The South Atlantic Anomaly throughout the Solar Cycle. Earth and Planetary Science Letters, 473, 154-163. https://doi.org/10.1016/j.epsl.2017.06.004

6. Tsutsumi, A. and Shirai, N. (2008) Electromagnetic Signals Associated with Stick-Slip of Quartz-Free Rocks. 
Tectonophysics, 450, 79-84. https://doi.org/10.1016/j.tecto.2008.01.001

7. He, L.M. and Kosuke, H. (2017) Ionospheric Anomalies Immediately before Mw7.0-8.0 Earthquakes. Journal of Geophysical Research: Space Physics, 122, 8659-8678. https://doi.org/10.1002/2017JA024012

8. Sotomayor-Beltran, C. (2019) Ionospheric Anomalies Preceding the Low-Latitude Earthquake That Occurred on April 16 2016, in Ecuador. The Journal of Atmospheric and Solar-Terrestrial Physics, 182, 61-66. https://doi.org/10.1016/j.jastp.2018.11.003

9. Zhang, X., et al. (2014) The Characteristics of Quasistatic Electric Field Perturbations Observed by Demeter Satellite before Large Earthquakes. Journal of Asian Earth Sciences, 79, 42-52. https://doi.org/10.1016/j.jseaes.2013.08.026

10. He, L. and Kosuke, H. (2016) Three-Dimensional Distribution of Ionospheric Anomalies Prior to the Three Large Earthquakes in Chile. Geophysical Research Letters, 43, 7287-7293. https://doi.org/10.1002/2016GL069863

11. Shah, M. and Jin, S. (2015) Statistical Characteristics of Seismo-Ionospheric GPS TEC Disturbances Prior to Global Mw $\geq 5.0$ Earthquakes (1998-2014). Journal of Geodynamics, 92, 42-44.

https://doi.org/10.1016/j.jog.2015.10.002

12. Sotomayor-Beltran, C. (2019) Positive and Negative Ionospheric Disturbances Prior to the 2016 Christmas Earthquake in Chile. Geomatics, Natural Hazards and Risk, 10, 622-632. https://doi.org/10.1080/19475705.2018.1536081

13. Zou, Y. and Zhao, T. (2007) Ionospheric Anomalies Detected by GPS TEC Measurements during the 15 August 2007, Peru Earthquake.

14. Hu, H. and Gao, Y. (2011) Electromagnetic Field Generated by a Finite Fault Due to Electrokinetic Effect. Journal of Geophysical Research, 116, B08302. https://doi.org/10.1029/2010JB007958

15. Ren, H., et al. (2015) Electrokinetic Effect Combined with Surface-Charge Assumption a Possible Generation Mechanism of Coseismic-EM Signals. Geophysical Journal International, 200, 835-848.

https://doi.org/10.1093/gji/ggu435

16. Freund, F.T., et al. (2006) Electric Currents Streaming out of Stressed Igneous Rocks. A Step towards Understanding Pre-Earthquakes Low Frequency EM Emissions. Physics and Chemistry of the Earth, 31, 389-396. https://doi.org/10.1016/j.pce.2006.02.027

17. Muto, J., et al. (2007) Frictional Discharge at Fault Asperities: Origin of Fractal Seismo-Electromagnetic Radiation. Tectonophysics, 43, 113-122. https://doi.org/10.1016/j.tecto.2006.05.045

18. Heki, K. and Ping, J. (2005) Directivity and Apparent Velocity of Coseismic Ionospheric Disturbances Observed with a Dense GPS Array. Earth and Planetary Science Letters, 236, 845-855.

https://doi.org/10.1016/j.epsl.2005.06.010

19. Heki, K., et al. (2006) Detection of Ruptures of Andaman Faults Segments in the 2004 Great Sumatra Earthquake with Coseismic Ionospheric Disturbances. Journal of Geophysical Research, 111, B09313. https://doi.org/10.1029/2005JB004202

20. Rolland, M.L., et al. (2011) The Resonant Response of the Ionosphere Imaged after the 2011 off the Pacific Coast of Tohoku Earthquake. Earth Planets Space, 63, 853-857. https://doi.org/10.5047/eps.2011.06.020

21. USGS. https://earthquake.usgs.gov/earthquakes/search

22. IRIS. http://www.iris.edu

23. Cataldi, G., et al. (2017) SELF-VLF Electromagnetic Signals and Solar Wind Proton Density Variations That Preceded the M6.2 Central Italy Earthquake on August 24, 2016. International Journal of Modern Research in Electrical and Electronic Engineering, 1, 1-15. https://doi.org/10.20448/journal.526/2017.1.1/526.1.1.15

24. Meloni, A., et al. (2004) Tectonomagnetic and VLF Electromagnetic Signals in Central Italy. Annals of Geophysics, 47, 29-37. 